\title{
How do the cardiology services for patients presenting with acute coronary syndromes compare between developing and developed countries?
}

\section{Reflective Report with Case Comparison}

\author{
Dominic Mears \\ Corresponding Author: Dominic Mears \\ University of Birmingham, United Kingdom \\ Email: drmears@btinternet.com
}

Cite this article as: Mears D. How do the cardiology services for patients presenting with acute coronary syndromes compare between developing and developed countries? Nepalese Heart Journal 2019; Vol 16(1), 1-6

Received date: 21 st November 2018

Accepted date: 2nd April 2019

Abstract

Background and Aims: Acute Coronary Syndromes (ACS) represent a significant challenge for healthcare systems worldwide, however there is a vast disparity between developed and developing countries in terms of their management and subsequent patient outcomes. The aim of this reflective report was to explore the services provided for ACS patients in the developing country Nepal and compare them to the highly developed United Kingdom. This was with a view to summarise the priorities for Nepal going forward in addressing this major public health challenge and improving their ACS patient outcomes.

Methods: This reflective report was constructed following an elective placement at the Shahid Gangalal National Heart Centre in Kathmandu, Nepal. It involved collecting numerous ACS patient case studies from the United Kingdom (UK) and Nepal and reflecting on their clinical experiences using the Gibbs Reflective Cycle.

Reflective Summary: The treatment strategies for ACS are very similar in both countries, however in Nepal it is more difficult to efficiently transport patients into hospital and the population is less aware of the symptoms of ACS, thus contributing to delayed presentations and poorer outcomes. Furthermore, the provision of non-emergency healthcare, collection of patient data and general hospital resources were understandably deficient in comparison to the UK given the difference in financial status.

Discussion: In order to address the rising incidence of ACS, Nepal should prioritise investment in the hospital facilities provided for these patients, including suitably equipped emergency transport and cardiac catheterisation laboratories. In addition, they should work towards an electronic patient database and more established non-emergency healthcare services. Perhaps most importantly is the need for improved health promotion about the risk factors for ACS and the signs of a heart attack.

Keywords: Acute coronary syndromes, cardiology services, developing and developed countries.

DOI: https://doi.org/10.3126/njh.v16i1.23887

\section{Introduction}

Coronary Heart Disease (CHD) is well established as the leading cause of death worldwide, making it arguably the most serious non-communicable disease that healthcare systems have to contend with ${ }^{1}$. In the United Kingdom (UK) alone, 66,000 people a year die from CHD and the vast majority of these deaths are due to a myocardial infarction. ${ }^{1}$ In developed countries such as the UK, years of experience in treating myocardial infarctions as well as subsequent research and public awareness of the risk factors have contributed to a vastly improved survival rate e.g. compared to the 1960's when 7 out of 10 people suffering a myocardial infarction died, nowadays 7 out of 10 people survive ${ }^{1}$. The most serious form of CHD is acute coronary syndrome (ACS), when an atherosclerotic plaque ruptures and blocks coronary arteries. ${ }^{2}$ ACS describes a spectrum of clinical presentations resulting from severe coronary artery occlusion leading to myocardial ischaemia or infarction. ${ }^{2}$ ACS is divided into Unstable Angina, Non-ST Elevation Myocardial Infarction (NSTEMI) and ST Elevation Myocardial Infarction (STEMI) depending on the ECG changes observed and blood troponin level, with STEMI being by far the most life threatening. ${ }^{3}$ The overall incidence of ACS is actually declining in the $\mathrm{UK}^{4}$, whereas in developing countries the incidence is rising considerably and healthcare

@Nepalese Heart Journal. Nepalese Heart Journal retains copyright and work is simultaneously licensed under Creative Commons Attribution License CC - BY 4.0 that allows others to share the work with an acknowledgement of the work's authorship and initial publication in this journal. 
systems are having to adapt to suit. ${ }^{5}$ This rise in ACS is attributed to the increase in risk factors associated with the urbanisation of developing countries e.g. smoking, obesity, sedentary lifestyle, dyslipidemia, hypertension and diabetes mellitus. ${ }^{5}$ This trend is well demonstrated in Nepal, which is experiencing a startling rise in the prevalence of metabolic syndrome (hypertension, obesity and diabetes) as it continues to develop. ${ }^{6}$ Compared to the UK, ACS in developing countries affects patients at a younger age and the mortality is higher. ${ }^{5}$ Recent literature suggests that this is due to the lack of access to suitable treatments as well as the increase in risk factors for $\mathrm{CHD}^{5}$, so the cardiology services available are of critical importance in addressing the worsening problem of ACS in developing countries.

The optimum treatment for an acute STEMI (where a coronary artery is totally occluded) involves early diagnosis and rapid reperfusion via primary percutaneous coronary intervention (PPCI) or thrombolysis within 12 hours of the onset of chest pain. $^{2}$ The best long term outcomes are achieved with PPCI rather than thrombolysis and patients with particularly severe coronary artery disease should be considered for coronary bypass surgery $^{2}$. These interventions will be performed in conjunction with loading doses of aspirin and another antiplatelet along with other supportive measures e.g. high flow oxygen, nitrates, analgesia and anti-emetics. With NSTEMI and Unstable Angina (corresponding to a partial occlusion of a coronary artery), the interventions are ultimately very similar but less time critical e.g. within 24-72 hours usually. ${ }^{2}$

In the UK, cardiology services for STEMI are scrupulously organised according to the mantra of "time is muscle"; this is an approach advocated worldwide in order to achieve better outcomes for STEMI patients by reducing the amount of time that their myocardium remains ischaemic. ${ }^{7}$ Every step of the patient journey is streamlined in order to reduce the amount of time from the patient experiencing chest pain to receiving PPCI, thus requiring a carefully co-ordinated effort between the hospital, emergency services and telephone operators. ${ }^{2}$ There are dedicated coronary care units (CCU) with the capacity for continuous ECG monitoring and defibrillation that are ready to receive patients at any time, thus playing a crucial role in achieving better outcomes for these patients. ${ }^{2}$

The objective of this report is to compare the cardiology services for ACS in the UK to a developing country, taking into account the vastly different financial statuses. The Shahid Gangalal National Heart Centre (SGNHC) in Kathmandu, Nepal is the first tertiary centre for cardiovascular disease in Nepal and receives referrals from all around the country, making it an ideal hospital to compare to. ${ }^{8}$
Current evidence points to a lack of awareness of the risk factors for ACS and the signs and symptoms amongst the Nepalese population, thus causing patients to present with ACS very late and limiting their treatment options; this probably contributes to an increased mortality rate from ACS. ${ }^{9}$ There is however little convincing evidence exploring the actual hospital care provided for acute coronary syndromes in developing countries ${ }^{10}$, with several recent studies that investigated possible quality improvement interventions for ACS services finding inconclusive results. ${ }^{10}$ The aim was therefore to explore the services provided in more depth during my elective placement at SGNHC in order to find out their strengths and weaknesses.

The SGNHC Annual Report $2017^{11}$ advocates its 12-bed CCU department with 24 hour on call cover but also eludes to the role that patient affordability plays in treatment choice. This is a very unfamiliar concept to me as a medical student training in the National Health Service (NHS) in the UK, so this was a factor that I was very keen to investigate. I anticipated that the objectives of ACS interventions would be similar in Nepal but the actual process would probably be less streamlined and efficient.

The primary aim of this project was to reflect on the clinical experiences of ACS patients observed on my elective and in the UK and use this to draw attention to the aspects of the cardiology services in Nepal that should be prioritised for improvement in the future.

\section{Method}

In this reflective report, I will be comparing my experiences of the cardiology services provided for patients suffering from ACS in Nepal and the UK. In order to do this, I took histories from and examined numerous ACS patients in each country and evaluated the components of their patient journey using a basic template (see figures 1, 2 \& 3 below). I collected ACS patient case studies for each type of ACS (Unstable Angina, NSTEMI and STEMI), picked the most typical case and formulated them into a comparative table for each country (see figures 1, 2 and 3). This was designed to provide a simple and clear format for making comparisons and to facilitate thorough and accurate reflections on the cardiology services provided to these patients throughout the report.

I will reflect on my experiences of meeting these patients using the Gibbs Reflective Cycle ${ }^{12}$ to structure my points. This model consists of 6 chronological stages of reflection (description, feelings, evaluation, analysis, conclusion and action plan) that will be applied to each scenario.

These reflections will then inform the discussion where I will underline the key differences between the two countries and the priorities for Nepal going forward in addressing their rising incidence of ACS. 
Figure 1: Patient Case Study Comparison: STEMI:

\begin{tabular}{|c|c|c|}
\hline Case Study & UK & Nepal \\
\hline Age & 83 & 72 \\
\hline Sex & Male & Male \\
\hline $\begin{array}{l}\text { Presenting } \\
\text { Complaint }\end{array}$ & $\begin{array}{l}\text { Sharp retrosternal chest pain that came on at rest. Described as } \\
\text { burning sensation, no radiation to shoulders, arms or neck and not } \\
\text { affected by breathing. No shortness of breath, dizziness or syncope. }\end{array}$ & $\begin{array}{l}\text { Chest pain radiating down the left arm and shoulder } \\
\text { that came on at rest. Accompanied by palpitations } \\
\text { and shortness of breath. No nausea, vomiting, loss } \\
\text { of consciousness or sweating described. }\end{array}$ \\
\hline $\begin{array}{l}\text { History of } \\
\text { Presenting } \\
\text { Complaint }\end{array}$ & $\begin{array}{l}\text { Had a few similar episodes intermittently in weeks leading up to this } \\
\text { event. Usually settled with rest. This episode was more severe so } \\
\text { patient called ambulance after } 5 \text { minutes of pain onset. }\end{array}$ & $\begin{array}{l}\text { The patient presented to the Outpatient } \\
\text { Department at SGNHC following } 5 \text { months } \\
\text { of ongoing exertional chest pain that had got } \\
\text { significantly worse over the past 5-7 days, } \\
\text { progressing to severe chest pain occurring at rest. } \\
\text { He was subsequently admitted to the Emergency } \\
\text { Department. }\end{array}$ \\
\hline $\begin{array}{l}\text { Journey to } \\
\text { Hospital }\end{array}$ & $\begin{array}{l}\text { Phoned } 111 \text { and ambulance was sent immediately based on } \\
\text { symptoms. }\end{array}$ & $\begin{array}{l}\text { Very late presentation due to far distance from } \\
\text { hospital ( } 6 \text { hours away via public transport) and } \\
\text { assumption that it was nothing serious - thought it } \\
\text { was acid reflux. }\end{array}$ \\
\hline Diagnosis & $\begin{array}{l}\text { ECG in ambulance showed Inferior Wall STEMI (ST elevation in } \\
\text { leads II, III \& aVF) }\end{array}$ & $\begin{array}{l}\text { Upon admission, patient was investigated as } \\
\text { follows: Chest X-ray (normal), Echocardiogram } \\
\text { (showed Anteroseptal wall hypokinesia), ECG (ST } \\
\text { Elevation in V1-V3, with reciprocal changes in } \\
\text { lead II and aVF) and Cardiac Enzymes (raised). } \\
\text { Subsequently diagnosed with late presentation } \\
\text { Anterior Wall STEMI. }\end{array}$ \\
\hline Management & $\begin{array}{l}\text { Rushed to Cath Lab within } 20 \text { minutes of initial phone call. } \\
\text { Loaded with Aspirin and Ticagrelor plus a Low Molecular Weight } \\
\text { Heparin (LMWH) and then had three stents inserted due to severe } \\
\text { stenosis of the Right Coronary Artery. Followed up in CCU with } \\
\text { an echocardiogram and multi-disciplinary team discussion about } \\
\text { the potential need for bypass surgery. Started on a Beta Blocker } \\
\text { (Bisoprolol). Had Lung Function Tests, a Carotid Doppler and was } \\
\text { eventually discharged. }\end{array}$ & $\begin{array}{l}\text { Managed with loading doses of Aspirin and } \\
\text { Clopidogrel, Nitrates and an injection of a Low } \\
\text { Molecular Weight Heparin (LMWH). } \\
\text { Referred for an elective angiography +/- PCI } 7 \text { days } \\
\text { after admission. The angiogram revealed severe } \\
\text { triple vessel disease and he was hence referred for } \\
\text { bypass surgery. }\end{array}$ \\
\hline
\end{tabular}

Figure 2: Case Study Comparison: NSTEMI:

\begin{tabular}{|c|c|c|}
\hline Case Study & UK & Nepal \\
\hline Age & 61 & 61 \\
\hline Sex & Male & Male \\
\hline $\begin{array}{l}\text { Presenting } \\
\text { Complaint }\end{array}$ & $\begin{array}{l}\text { Right sided chest pain at rest for } 1 \text { hour. Felt } \\
\text { like a tight band around chest and accompanied } \\
\text { by shortness of breath. No nausea, vomiting or } \\
\text { sweating. No dizziness, syncope or collapse. }\end{array}$ & $\begin{array}{l}\text { Persistent left shoulder and arm pain for } 5 \text { days. No chest pain } \\
\text { described. No shortness of breath, sweating, pain on inspiration, loss } \\
\text { of consciousness, nausea \& vomiting or palpitations. }\end{array}$ \\
\hline $\begin{array}{l}\text { History of } \\
\text { Presenting } \\
\text { Complaint }\end{array}$ & $\begin{array}{l}\text { On-off chest pain for a month prior to this } \\
\text { episode. }\end{array}$ & No preceding symptoms. \\
\hline $\begin{array}{l}\text { Journey into } \\
\text { Hospital }\end{array}$ & Came into hospital via ambulance. & The patient came into hospital via own transport. \\
\hline Diagnosis & $\begin{array}{l}\text { No ECG changes found in ambulance but } \\
\text { Troponins raised, so NSTEMI diagnosed. Had } \\
\text { non-urgent angiography within } 48 \text { hours and was } \\
\text { also investigated for Pulmonary Embolism with } \\
\text { D-Dimer test and CT Pulmonary Angiogram. }\end{array}$ & $\begin{array}{l}\text { Investigated with an ECG in the Emergency Room that showed } \\
\text { no acute ST changes but T wave inversion in leads II, III and } \\
\text { aVF. Troponins were positive. Chest X-Ray was normal and } \\
\text { Echocardiogram showed no regional wall abnormalities and grade } \\
\text { I diastolic dysfunction. The patient was hence diagnosed with an } \\
\text { NSTEMI. }\end{array}$ \\
\hline Management & $\begin{array}{l}\text { Referred for Bypass Surgery based on severe triple } \\
\text { vessel disease revealed on angiography. } \\
\text { Followed up with an echocardiogram and carotid } \\
\text { doppler. Put on Aspirin, Ticagrelor, Bisoprolol } \\
\text { and Nitrates. }\end{array}$ & $\begin{array}{l}\text { Treated acutely with } 300 \mathrm{mg} \text { of Ecosprin and Clopidogrel, along with } \\
\text { nitrates. Started on a Low Molecular Weight Heparin, Statin, ACE } \\
\text { Inhibitor, Beta Blocker and Proton Pump Inhibitor. Referred for an } \\
\text { angiography } 3 \text { days after presentation that revealed severe stenosis } \\
\text { of the Right Coronary Artery. Planned for PCI to this artery pending } \\
\text { financial arrangements. }\end{array}$ \\
\hline
\end{tabular}


Figure 3: Case Study Comparison: Unstable Angina

\begin{tabular}{|c|c|c|}
\hline Case Study & UK & Nepal \\
\hline Age & 77 & 42 \\
\hline Sex & Female & Female \\
\hline $\begin{array}{l}\text { Presenting } \\
\text { Complaint }\end{array}$ & $\begin{array}{l}\text { Central chest pain that radiated to her neck and down } \\
\text { both arms, described as a tight band around her chest. } \\
\text { Associated shortness of breath, nausea but no vomiting. } \\
\text { No syncope, collapse, palpitations or weakness. }\end{array}$ & $\begin{array}{l}\text { Worsening exertional central chest pain that was relieved } \\
\text { by rest. The pain did not radiate and was accompanied by } \\
\text { shortness of breath. No loss of consciousness, nausea \& } \\
\text { vomiting or changes upon inspiration. }\end{array}$ \\
\hline $\begin{array}{l}\text { History of } \\
\text { Presenting } \\
\text { Complaint }\end{array}$ & $\begin{array}{l}\text { 6-8 week history of worsening episodes of chest pain upon } \\
\text { exertion, culminating in an extremely painful episode of } \\
\text { sudden onset left sided chest pain at rest for } 1 \text { hour. }\end{array}$ & Pain persisted for 7 days "on and off" prior to admission. \\
\hline $\begin{array}{l}\text { Journey into } \\
\text { Hospital }\end{array}$ & Emergency ambulance & Patient was transported via taxi to hospital. \\
\hline Diagnosis & $\begin{array}{l}\text { ECG in ambulance showed no acute changes with a pre- } \\
\text { existing left bundle branch block and left axis deviation. } \\
\text { Troponins were negative. Chest X-Ray and Echo } \\
\text { unremarkable. The patient was hence diagnosed with } \\
\text { unstable angina. }\end{array}$ & $\begin{array}{l}\text { ECG in emergency department showed T wave inversion } \\
\text { in V3 \& V4 but otherwise normal. } \\
\text { Chest X-Ray (Normal), Echocardiogram and Troponins } \\
\text { were normal. } \\
\text { Diagnosis of unstable angina made. }\end{array}$ \\
\hline Management & $\begin{array}{l}\text { Morphine to manage her pain, Sublingual GTN and a } \\
\text { loading dose of Aspirin and Clopidogrel before being } \\
\text { referred for a routine coronary angiogram +/- PCI } 24 \text { hours } \\
\text { post admission. The angiogram revealed minor coronary } \\
\text { artery disease, and no further stents were inserted. She was } \\
\text { hence medically managed. }\end{array}$ & $\begin{array}{l}\text { Management was originally IV STAT dose of a Proton } \\
\text { Pump Inhibitor because of presumed GORD. Then } \\
\text { Ecosprin and Clopidogrel were given (300mg each) once } \\
\text { Unstable Angina Diagnosis confirmed. Also put on } \\
\text { atorvastatin and referred for a CT Coronary Angiogram to } \\
\text { assess patency of coronary arteries. } \\
\text { Found normal coronary arteries and discharged. }\end{array}$ \\
\hline
\end{tabular}

\section{Reflective Summary}

The different components of the ACS services in Nepal and the UK that I have chosen to compare and reflect on can be divided into hospital factors and patient factors.

\section{Hospital Factors:}

At SGNHC, I observed that the level of documentation was very different to the UK in that there are no electronic records of patient data. The paper based system certainly functioned in the acute setting, however I speculated that patient medical details would be more difficult to summarise and navigate than a digital one. In practice, the doctors and patients were used to this system and it didn't seem to interfere with the healthcare delivered, however the paper records mean that is a challenge to process and analyse data in order to improve their services. In contrast to the wealth of computer based patient data that the UK constantly collects, audits and utilizes for its quality improvement, SGNHC has no similar database to do this. This could potentially inhibit the continuous improvement of their ACS services because they are not able to formally analyse the parts of the patient journey that are less efficient. In order to address this, SGNHC are attempting to implement a paper based STEMI registry by adding paper inserts to the clinical notes of known STEMI patients with 40 different variables to record. This is still a relatively unreliable paper based system, so the long term target should be to switch to a computerized database and utilise this to their advantage. There is also literature to suggest that computer based patient record systems encourage clinicians to document patient notes more thoroughly and accurately. ${ }^{13}$

My supervisor explained to me that their hospital is heavily reliant on the evidence based guidelines provided by Europe and America to inform their practice. This certainly has the benefit of adhering to perceived best practice but also means that the doctors in Nepal are relying on evidence that isn't based in their own endemic population or healthcare system, so it could be less relevant and cost-effective. In spite of this, the fact that advanced potentially life-saving facilities are available at SGNHC is a positive step for a developing country with limited funding resources.

With the development of their own computerized database, it is hoped that in the future, SGNHC might be able to conduct its own rigorous academic research into the best possible ACS interventions for the Nepalese population and thus adapt their healthcare resources to suit.

In terms of the actual management strategies once the ACS patients were admitted to hospital, these were very similar in the UK and Nepal. There is a Cardiac Catheterisation Laboratory (Cath Lab) at SGNHC with full time on call cover and hence the facility to perform emergency PPCI on demand for STEMI patients with highly effective drug eluting stents; furthermore the medications delivered were extremely similar to those used in Western Medicine e.g. dual antiplatelets, low molecular weight heparins, nitrates, beta blockers and ACE Inhibitors. ${ }^{2}$ I was fairly impressed that these patients were being managed optimally according to the latest evidence. It is worth noting that although revascularisation therapy is available at SGNHC, it can take longer for ACS patients who are not suitable for emergency PPCI to receive this intervention as an elective procedure compared to in the UK. Figures 1, 2 and 3 portray how Nepalese ACS patients had to wait 3-7 days for an elective angiography compared to 1-2 days in the UK. I felt that this could be detrimental to this group of patients considering that the evidence base points to an optimum time window of $24-72$ hours for this intervention. ${ }^{2}$ It is likely that this delay is due to the more limited access to the Cath Lab associated with a developing country where demand for these services far exceeds supply. In 
order to meet this demand in the future, Nepal would benefit from investment in their healthcare system so that more centres will have the resources and staff to perform prompt revascularisation on ACS patients within the recommended time window.

A major difference between the healthcare systems in the UK and Nepal is the relative deficiency of non-emergency medical care services in Nepal. I was interested to discover that nonemergency medical care can only be sought via directly attending the outpatient department of the hospital at SGNHC. There were enormous queues outside the outpatient department every day and my experiences in clinic revealed very brief consultations without much time to explore patient problems, although they were conducted with highly astute clinical proficiency. Whilst having all outpatient services provided by the hospital avoids complicated referral systems between non-emergency community services and hospital based emergency care, it also means that the demand on the hospital outpatient department is overwhelming. General Practitioners (Family Physicians) in the UK play a vital role in lessening the demand on hospitals and educating patients about the risk factors for cardiac disease or the signs of a heart attack. Furthermore, community healthcare services can play a vital role in patient rehabilitation post myocardial infarction, something with a convincing evidence base for improved outcomes..$^{14}$ Community based rehabilitation has been shown to have comparable outcomes to similar hospital based services ${ }^{15}$, so there is potentially scope to reduce demand on hospitals by shifting these services out to the community. Although rehabilitation services do exist at SGNHC ${ }^{11}$, the fact that they are hospital based means that is very difficult to reach the wider populations of Nepal. The development of effective community based non-emergency services could lessen the demand on hospitals such as SGNHC and free up more resources to manage patients with ACS.

\section{Patient Factors:}

The biggest challenge that the ACS services in Nepal have to face is the late stage of presentation of their patients. Figure 1 demonstrates how a Nepalese patient presented with a STEMI after 6 months of worsening exertional chest pain culminating in 7 days of pain at rest; this is in stark contrast to the UK patient who was admitted to the Cath Lab within 30 minutes of experiencing chest pain. There is evidently a vast difference in the presentation stage of patients in developing and developed countries. Delayed presentation of STEMI is associated with poorer outcomes because the most effective treatments (PPCI and Thrombolysis) are not as beneficial ${ }^{16}$, although there is evidence to suggest that delayed presentation is less of a problem for NSTEMI patients ${ }^{17}$. Witnessing patients who had presented at such a late stage was very humbling given my experiences in the UK of astoundingly rapid interventions for the exact same disease. Previous research in Nepal points to a lack of awareness of the signs of ACS amongst the population and difficulties with getting to a hospital as the key reasons behind their late presentation ${ }^{16}$. The consensus is that if patients do make it to hospital, they tend to do fairly well ${ }^{11}$. Regardless of the facilities available at the hospital, there is a clear need for more healthcare centres with the facility to perform PPCI around the country.

There is also a need to promote healthy lifestyles, however this is very challenging because Nepal is such a remote country with numerous different geographical regions and dialects spoken. As the country develops, it should become easier to communicate these messages via television and internet rather than the more old fashioned measures such as radio, posters and leaflets currently being used.
An aspect of the ACS services in Nepal that I was particularly keen to experience was the role of patient affordability in determining treatment choice. Nepal has a mix of public and private hospitals and the state seeks to support all hospitals with as much of a contribution as it can afford ${ }^{18}$, but inevitably there is still a significant cost to healthcare in a poor country. SGNHC is a semi-government hospital that receives funding from the state, so patient wealth arguably has the potential to directly influence clinical decision-making. Whilst it's highly encouraging that Nepal has the facility to perform these advanced healthcare procedures, like many Asian developing countries, patient affordability is a major barrier to accessing them. ${ }^{19}$ As Nepal's economy grows, the cost of interventions for ACS should become less expensive and more widely available to its population. It would hence be advisable for SGNHC to lobby for increased government financial contributions to ACS services given the burden that this particular disease is putting on their healthcare system.

The final area of stark contrast between the ACS services in Nepal and the UK is the way that patients are transported into hospital. In the UK, an ambulance can be sent within minutes and a suspected ACS patient will receive an ECG in the vehicle (as evidenced by figures 1,2 and 3 ) in order to determine if they need to activate the Cath Lab ready to perform emergency PPCI upon the patient's arrival.

In Nepal, 102 is the hotline number for emergency ambulance services. The ambulances at SGNHC were fairly rudimentary and had no capacity for ECG recording; they also have to combat the very congested roads in Kathmandu, meaning that it can take hours to retrieve patients from some parts of the city. Because of this, patients tend to choose personal or public transport because it is relatively quick compared to taking an ambulance - especially if they live outside of the city. Often patients from rural Nepal commute for hours if not days to access a suitable hospital and it is a very common reason for delayed presentation and subsequent poorer outcomes in ACS patients ${ }^{19}$. It should be a public health priority to have a well-publicised emergency phone number that triggers an ambulance from the local area to collect a patient promptly and efficiently. In addition, minimal investment could provide ECG machines for ambulances so that Cath Labs could be activated in advance of a patient arriving at hospital or thrombolysis given at the scene if PPCI is unavailable within the optimum time window. This would give patients suffering from an acute STEMI the best chance of survival.

\section{Discussion}

Overall, the cardiology services for ACS at SGNHC in a developing country were comparable to the highly developed UK in terms of the management strategies offered. The key differences in Nepal are the late presentation stage of the patients, the challenging emergency transport to hospital and the role of patient affordability in determining treatment choice. There are also notable differences in the way that patient information is recorded and the lack of non-emergency healthcare services to relieve the demand on hospitals in Nepal. Although these points are based on experiences of just one hospital in a developing country, previous literature appears to reflect similar problems across the Asia-Pacific region. ${ }^{19}$ Such is the lack of digital patient records, it is very challenging to scrupulously analyse the key features of these services that are underperforming.

From reflecting on my experiences of the ACS services in Nepal, I think that the priorities going forward are as follows: 
1. Seek further funding from the government to reduce the patient cost of undergoing invasive coronary procedures and minimise the role that patient affordability plays in determining treatment choice.

2. Equip ambulances with ECG machines so that patients suffering from a STEMI can be immediately transferred to a Cath Lab for PPCI

3. Move towards electronic patient records in order to accurately record and analyse data and promote future research.

4. Establish basic non-emergency community healthcare services in order to relieve the burden on hospitals.

5 Educate the population about the risk factors for coronary artery disease and signs and symptoms of ACS via television and the internet, thus encouraging patients to present earlier.

6 Equip more health centres in Nepal with interventional cardiology facilities so that patients can access the best ACS treatments more readily.

Combatting the alarming rise in ACS incidence in Nepal and other developing countries represents a huge challenge, especially when financial resources are obviously limited. Thankfully, huge strides in this field have already been made over the past 20 years $^{20}$, so with comparatively little investment, it should be possible to establish excellent care for ACS patients worldwide in the future.

\section{Editor's Note}

This article represents the viewpoint of the author as an observer for a month in a cardiac institute and his reflection on the management of the cardiovascular disease. Though the comparison is done using the particular cases, this article does not reflect the day to day cases that is being managed by the cardiovascular team and the country in a large scale, in a limited resource with different geographic and economic hurdles. The author might not be aware of the different schemes, though partial, provided by the government has been much help for the patients in terms of treatment costs. However, the points mentioned by the author are very encouraging and reflective of the problems we are facing and the improvements we can achieve.

\section{References}

1. British Heart Foundation. (2018) CVD Statistics - BHF UK Factsheet. 2-5.

2. Ramrakha P, Hill J. Oxford Handbook of Cardiology. 2nd ed. UK: Oxford University Press; 2012; 254-309. https://doi.org/10.1093/med/9780199643219.001.0001

3. Gale C. Acute coronary syndrome in adults: scope of the problem in the UK. Br J Cardiol. 2017. 24;((suppl 1):S3-S9).

4. Timmis A. Acute Coronary Syndromes. BMJ. 2015; 351(h5153). https://doi.org/10.1136/bmj.h5153

5. Gaziano TA, Bitton A, Anand S, et al. Growing Epidemic of Coronary Heart Disease in Low- and Middle-Income Countries. Current Problems in Cardiology. 2010; 35(2):72115. https://doi.org/10.1016/j.cpcardiol.2009.10.002

6. Sharma SK, Ghimire A, Radhakrishnan J, et al. Prevalence of Hypertension, Obesity, Diabetes, and Metabolic Syndrome in Nepal. International Journal of Hypertension. 2011:1-9. https://doi.org/10.4061/2011/821971

7. Antman EM. Time Is Muscle: Translation Into Practice. Journal of the American College of Cardiology. 2008; 7;52(15):1216-1221.

https://doi.org/10.1016/j.jacc.2008.07.011

8. Shahid Gangalal National Heart Centre. Official website. [internet]. 2018 [cited 2018 July 5]; [1 screen]. Available at: https://www.sgnhc.org.np/.
9. Vaidya A, Aryal UR, Krettek A. Cardiovascular health knowledge, attitude and practice/behaviour in an urbanising community of Nepal: a population-based cross-sectional study from Jhaukhel-Duwakot Health Demographic Surveillance Site. BMJ open. 2013; 3(10):e002976. https://doi.org/10.1136/bmjopen-2013-002976

10. Lee ES, Vedanthan R, Jeemon P, et.al. Quality Improvement for Cardiovascular Disease Care in Low- and MiddleIncome Countries: A Systematic Review. PLoS One. 2016; 11(6): 0157036. https://doi.org/10.1371/journal.pone.0157036

11. Manandhar R, Silwal P, Pandey R. Shahid Gangalal National Heart Centre Annual Report; Acute Coronary Syndrome. Shahid Gangalal National Heart Centre 2017:20-21.

12. Gibbs G. Learning By Doing: A Guide to Teaching and Learning Methods. Oxford: Oxford Further Education Unit; 1988.

13. Tang PC, LaRosa MP, Gorden SM. Use of Computerbased Records, Completeness of Documentation, and Appropriateness of Documented Clinical Decisions. Journal of the American Medical Informatics Association. 1999; 6(3): 245-251. https://doi.org/10.1136/jamia.1999.0060245

14. Rauch B, Davos CH, Doherty P, et.al. The prognostic effect of cardiac rehabilitation in the era of acute revascularisation and statin therapy: A systematic review and meta-analysis of randomized and non-randomized studies - The Cardiac Rehabilitation Outcome Study (CROS). Eur J Prev Cardiol. 2016; 23(18): 1914-1939. https://doi.org/10.1177/2047487316671181

15. Bertelsen JB, Refsgaard J, Kanstrup H, et al. Cardiac rehabilitation after acute coronary syndrome comparing adherence and risk factor modification in a communitybased shared care model versus hospital-based care in a randomised controlled trial with 12 months of follow-up. Eur J Cardiovasc Nurs. 2017; 16(4): 334-343. https://doi.org/10.1177/1474515116666781

16. Acharya P, Adhikari RR, Bhattarai J, et al. Delayed presentation of acute coronary syndrome: a challenge in its early management. JNMA J Nepal Med Assoc. 2009; 48(173): 1-4. https://doi.org/10.31729/jnma.173

17. Elbarouni B, Goodman SG, Yan RT, et al. Impact of delayed presentation on management and outcome of non-STelevation acute coronary syndromes. Am Heart J. 2008; 156(2): 262-8. https://doi.org/10.1016/j.ahj.2008.03.025

18. World Health Organisation. Health System in Nepal: Challenges and Strategic Options (2007) [cited 2018 Aug 16]. Available from: http://apps.searo.who.int/pds_docs/B1361.pdf

19. Huo $\mathrm{Y}$, Thompson $\mathrm{P}$, Buddhari $\mathrm{W}$, et al. Challenges and solutions in medically managed ACS in the Asia-Pacific region: expert recommendations from the Asia-Pacific ACS Medical Management Working Group. Int J Cardiol. 2015; 183: 63-75. https://doi.org/10.1016/j.ijcard.2014.11.195

20. Shrestha N, Pilgrim T, Basnet A, et al. Percutaneous coronary intervention for acute coronary syndromes in eastern Nepal: a preliminary report. Swiss Med Weekly. 2013; 143;w13737. https://doi.org/10.4414/smw.2013.13737 